\title{
O Que é Um Bom Médico?
}

\section{How to Define a Good Doctor?}

José PONTE $\triangle^{1}$

Acta Med Port 2019 Sep;32(9):565-567 - https://doi.org/10.20344/amp.12033

Palavras-chave: Avaliação Educacional; Currículo Médico; Educação; Escolas Médicas; Internato Médico; Médicos; Modelos Educacionais; Portugal

Keywords: Curriculum; Education, Medical; Educational Measurement; Models, Educational; Physicians; Portugal; Schools, Medical

Desde a entrada numa faculdade, formar um especialista em medicina leva normalmente entre 10 e 12 anos, dependendo da especialidade. Seis anos para o curso básico, e entre quatro a seis anos para o internato médico.

Sabe-se que é difícil definir objetivamente o que é 'qualidade' num médico recém-formado ou num especialista que terminou o seu internato, mas é largamente aceite, infelizmente, que as notas obtidas nos exames reflectem a qualidade.

O consenso atual, adotado por instituições reguladoras da educação médica em vários países ${ }^{1-3}$ define, por ordem de importância, três vertentes fundamentais (outcomes) da educação médica, aplicáveis a qualquer nível da formação: valores e comportamento profissionais, competências clínicas práticas, incluindo comunicação, e conhecimentos teóricos.

Para definir a qualidade ao longo destas três vertentes é indispensável expandir os métodos objetivos de avaliação para além dos conhecimentos teóricos, uma tarefa menos consensual, mas em rápida evolução. É bem sabido que os exames acabam por definir a aprendizagem. Desta forma, sem instalar métodos para avaliar o profissionalismo e as competências clínicas práticas, a aprendizagem nessas áreas fica comprometida. Muitos educadores médicos têm persistido, sobretudo nos últimos 50 anos, na procura de metodologias para avaliar 'qualidade' para além dos conhecimentos teóricos.

$\mathrm{Na}$ maior parte das escolas médicas os exames focam principalmente, muitas vezes exclusivamente, os conhecimentos teóricos dos estudantes. Nos últimos 60 - 70 anos foram progressivamente adotados os testes de escolha múltipla [Multiple Choice Questionaire (MCQ)] como ferramenta principal de avaliação na quase totalidade das escolas médicas. Mas lembremos que os MCQs foram primeiro utilizados pelo exército americano durante a Primeira Guerra Mundial e passaram muitos anos antes de serem universalmente reconhecidos como o método objetivo mais prático para avaliar conhecimentos. São particularmente convenientes quando o número de examinandos é grande, como é o caso na maioria das escolas médicas, pois prestam-se a um tratamento mecanizado.
Nas faculdades de medicina, os exames finais com um caso clínico à cabeceira do doente ou os exames orais são hoje muito pouco utilizados. Ocupariam uma proporção exagerada do trabalho do corpo docente e têm sido objeto de muitas críticas pela falta de objetividade e pela grande dispersão dos resultados, apontando-se sempre um elemento de viés e de 'sorte'. Consequentemente, o MCQ tomou lugar primordial na avaliação.

Nos exames finais das especialidades da Ordem dos Médicos (OM) é utilizada uma diversidade de métodos, para além do $M C Q$, incluindo exames orais e discussão de casos clínicos.

Em 1975 Ron Harden et al em Aberdeen e em Glasgow, na Escócia, publicaram um artigo seminal no British Medical Journal, ${ }^{4}$ demonstrando um método objectivo de avaliação das competências clínicas práticas dos estudantes de medicina [Objective, Structured Clinical Examination (OSCE)] que foi rapidamente validado e adotado pela quase totalidade das escolas médicas dos países anglo-saxónicos e em alguns outros países. À semelhança do MCQ, a metodologia do OSCE tem sido aperfeiçoada ao longo dos anos e tornou-se numa ferramenta de avaliação fundamental, igualmente importante nos exames finais de atribuição do título de especialista no mundo anglo-saxónico.

Tipicamente, o OSCE numa escola médica cobre cerca de 100 competências ou procedimentos, cujo domínio se considera importante em todos os médicos recém-formados. São exames de high stakes: é essencial passá-los para passar de ano e contam para a nota final.

Cada teste é composto geralmente de entre 6 a 20 'estações', a funcionar simultaneamente, sendo normalmente avaliadas 1 - 3 competências em cada estação, utilizando apenas 6 - 15 minutos, com um avaliador diferente em cada estação. A competência pode ser, por exemplo, medir a pressão arterial, fazer uma história de uma cefaleia ou um exame simples do ouvido externo. Os estudantes não sabem que estações vão 'sair' de cada vez, tendo que se preparar em todas as estações possíveis (cerca de 100). Nas diversas estações podem ser utilizados atores (medir a pressão arterial, história de cefaleia) e modelos de plástico (exame do ouvido externo). O sistema é rotativo, passando

\footnotetext{
1. Professor Emérito. Universidade do Algarve. Faro. Portugal.

$\triangle$ Autor correspondente: José Ponte. jmcrponte@gmail.com

Recebido: 08 de março de 2019 - Aceite: 08 de março de 2019 | Copyright @ Ordem dos Médicos 2019
} 
os estudantes de uma estação para a próxima de forma controlada com um sinal sonoro ativado a intervalos regulares.

Este método, aplicado sistematicamente durante o curso, garante que os estudantes não completarão a unidade curricular sem demonstrar um mínimo de competência nas áreas definidas (cerca de 100) em todos os anos. Não existem outras metodologias que garantam objetividade de avaliação em todas as áreas importantes da prática clínica, que se possam facilmente aplicar a grandes números de estudantes.

Tanto quanto eu saiba, nenhum dos colégios das especialidades da Ordem dos Médicos adotou, até à data, o OSCE no processo de avaliação. Se fosse aplicado nos exames finais do internato médico, medida sugerida recentemente por Marques TR et $a l,{ }^{5}$ o OSCE poderia também garantir que o título de especialista não seria atribuído sem os candidatos demonstrarem objetivamente um mínimo de competência nas manobras mais importantes e específicas em cada especialidade.

É evidente que a metodologia dos OSCE requer recursos humanos consideráveis e torna-se complexa em instituições com números elevados de estudantes. Mas vale a pena notar que o rácio qualidade/custo é muito elevado. Penso que não existem alternativas credíveis e que não requeiram custos ainda mais elevados, para garantir uma avaliação objetiva das competências clínicas práticas em todos os estudantes.

Contactei as oito escolas médicas em Portugal e obtive a seguinte informação sobre a utilização de OSCEs:

\section{Escola de Medicina da Universidade do Minho}

Utilizados no final do terceiro ano e a meio do sexto ano desde 2010, com valor sumativo; testes compostos por seis estações na área da semiologia. Em todos os outros anos são feitos testes com $3-4$ estações para avaliar competências em manobras práticas.

\section{Faculdade de Medicina da Universidade do Porto}

Os OSCEs tiveram início em dezembro de 2018 na cadeira de Propedêutica, no terceiro ano, como exame semestral com ponderação de $25 \%$, cuja aprovação não é necessária para aprovação global. Têm 3 a 4 estações de 15 minutos com pacientes-simulados treinados para esse efeito. Os avaliadores têm um treino sumário sobre a ficha de avaliação previamente ao exame. Em Obstetrícia e Ginecologia são realizados testes estruturados, desde 2004, semelhantes aos OSCE, alguns com simuladores, contribuindo $2-3$ de 20 valores.

\section{Instituto de Ciências Biomédicas Abel Salazar}

São utilizados nas unidades curriculares de Semiologia e Fisiopatologia I e II no terceiro ano do Mestrado Integrado em Medicina (MIM). Cada OSCE tem três estações, são realizados com apoio de simuladores e são sumativos. Todos os estudantes recebem previamente formação nos simuladores utilizados na avaliação sumativa, e todos os formadores têm igualmente formação para o efeito.

\section{Universidade da Beira Interior}

São utilizados nos terceiro, quarto e quinto anos (Fisiopatologia no terceiro ano e Terapêutica nos quarto e quinto anos), são empregues cerca de 20 estações com valor sumativo relativas a manobras práticas, incluindo comunicação; o uso de doentes simulados ainda não existe por enquanto.

\section{Faculdade de Medicina da Universidade de Coimbra}

Discutiu-se uma proposta, mas concluiu-se que dado o número muito elevado de estudantes não seria possível implementar OSCEs com os recursos humanos existentes.

\section{Faculdade de Medicina da Universidade de Lisboa}

São utilizados informalmente em algumas cadeiras, com valor formativo; há planos para uso mais alargado no futuro.

\section{NOVA Medical School — Faculdade de Ciências Médicas}

Há planos para uso futuro bem como trabalho em curso para estabelecer o método.

\section{Universidade do Algarve}

São utilizados desde a fundação do curso em 2009, inicialmente três vezes por ano em todos os anos; presentemente duas vezes em cada ano do curso, com valor sumativo; 8 a 10 estações em cada teste; cobrem 134 competências incluindo semiologia, comunicação e manobras práticas, com participação de atores treinados para simular doentes; os examinadores são treinados.

Observa-se que o uso sistemático de OSCEs para garantir a avaliação objetiva das competências clínicas práticas clínicas ainda não foi adotado de forma sistemática pela maioria das escolas médicas portuguesas. Por sistemático entende-se, testar competências abrangendo todos os aspetos práticos da clínica, desde a comunicação (o apresentar-se ao doente, solicitar autorização para o procedimento em questão, explicação do procedimento, responder às preocupações dos doentes) até ao procedimento correto de um exame do fundo do olho, à interpretação de um hemograma, ao executar uma avaliação de risco de suicídio, etc.

A terceira vertente fundamental que ajuda a definir a qualidade do médico, os valores e comportamento profissionais, está ainda mais longe de ser objetivamente avaliada universalmente, em parte por falta de metodologias objetivas equivalentes ao MCQ e ao OSCE. É uma avaliação que depende criticamente do rácio estudante: tutor, e do número de oportunidades para avaliar. Todos os avaliadores são individualmente passíveis de viés. A melhor aproximação a uma avaliação objetiva dos valores e comportamento profissional necessita de múltiplas avaliações, por múltiplos avaliadores e em contextos variados, para eventualmente convergir num consenso perto da objetividade. Para esse efeito seria necessário organizar o currículo 
de forma a todos os estudantes beneficiarem do contacto num rácio de 1:1 com vários tutores, múltiplas vezes, em múltiplas situações, durante o curso. Os próprios tutores teriam de ser treinados para esta tarefa de avaliação. É sem dúvida um objectivo ambicioso, mas possível de realizar se houver vontade e determinação.

Nos últimos 50 - 60 anos, os educadores médicos têm feito um esforço determinado para desenvolver metodologias que possam melhorar a 'qualidade' da educação

\section{REFERÊNCIAS}

1. The General Medical Council. Outcomes for graduates. [consultado 2019 mar 04]. Disponível em: https://www.gmc-uk.org/education/ standards-guidance-and-curricula/standards-and-outcomes/outcomesfor-graduates.

2. Framework. [consultado 2019 mar 05]. Disponível em: http://canmeds. royalcollege.ca/en/framework.

3. Accreditation Standards and Procedures. [consultado 2019 mar 05]. Disponível em: https://www.amc.org.au/accreditation-and-recognition/ accreditation-standards-and-procedures.

4. Harden RM, Stevenson M, Downe WW, Wilson GM. Assessment of médica. Avaliações objetivas dos estudantes ou dos internos nas três vertentes fundamentais do perfil do médico são consideradas essenciais para garantir essa qualidade. A introdução do OSCE em 1975 foi um marco fundamental. Mais recentemente, a introdução de novas metodologias como, por exemplo, o progress testing ${ }^{6}$ nas escolas médicas e o workplace based assessment ${ }^{7}$ (avaliação no ambiente de trabalho) nos internatos das especialidades, prometem progressos reais no sentido da objetividade.

clinical competence using objective structured examination. BMJ. 1975:1:447-51.

5. Marques TR, Laíns I, Martins MJ, Goiana-da-Silva F, Sampaio F, Pessanha I, et al. Evaluation of the Medical Board Exam in Portugal. Acta Med Port. 2018;31:670-9.

6. Freeman A, van der Vleuten C, Nouns Z, Rickets C. Progress testing internationally. Med Teach. 2010;32:451-5.

7. Norcini JJ. ABC of learning and teaching in medicine: workplace based assessment. BMJ. 2010;326:753-5. 